\title{
Clinical Study \\ Supporting Family Volunteers to Increase Retention and Recruitment
}

\begin{abstract}
Anne Wilson
School of Nursing, The University of Adelaide, Adelaide SA 5005, Australia

Correspondence should be addressed to Anne Wilson, anne.wilson@adelaide.edu.au

Received 4 October 2011; Accepted 1 November 2011

Academic Editors: E. C. Alexopoulos and B. J. Polivka

Copyright () 2012 Anne Wilson. This is an open access article distributed under the Creative Commons Attribution License, which permits unrestricted use, distribution, and reproduction in any medium, provided the original work is properly cited.

This study explored South Australian volunteers' motivations for volunteering, their satisfaction with volunteering, and their need for supportive structures. Primary data were collected from volunteers working for a self-funded charitable organisation. A selfenumerated questionnaire was distributed by mail; 214 were completed and returned (66.9\% response rate). Of the responding volunteers, $82 \%(n=174)$ were female. All were aged over 60 years (range: 63-76 years; mean: 68 years). Numerical data were entered into SPSS and analysed descriptively. Content analysis was applied to narrative data. Volunteers reported that they volunteered most often to help others, because they had spare time and because of what they received in return. Difficulties experienced included accessing continuing education and training. Organisations engaging volunteers have a responsibility to ensure that volunteers are adequately supported both in their day to day work and in training or education. Volunteers are able to become valued partners in service delivery.
\end{abstract}

\section{Introduction}

Volunteers represent a growing, but often undervalued, section of service delivery in many areas of the community, particularly in health care. Volunteer activity may be defined as any activity intended to help others that is provided without obligation and for which the volunteer does not receive pay or other material compensation [1]. Volunteers usually provide such assistance through a religious, charitable, or community organization and receive little reimbursement for their contribution. In South Australia, the participation of volunteers in supporting people in their homes is actively and visibly promoted through many agencies such as Meals on Wheels Incorporated, St John Australia, and Carers Australia. In addition, there also are many who contribute through other organisations and less formally by caring for family and friends. Without such generosity, many would suffer a more restrictive and isolated existence due to the norms of contemporary society. The potential savings for the health and social services has been estimated to be significant, with nonpaid labour being cost effective [2] as well as having other beneficial effects. In fact Tomas et al., [3] consider that volunteers are increasingly viewed as health agents. This seems to be linked to current reforms in health services and the reorientation towards primary health care.

According to Taggart et al., who conducted a study of the Sutherland Family Network, a volunteer home visiting project in the Sutherland Shire, Sydney, Australia, home visitation is undergoing a revival in health and welfare systems [4]. Such programmes utilizing volunteers are just one form of home visitation and a way of breaking down social and cultural barriers between the formal health care system and the client.

Community volunteers' scope of care is diverse, and they are often challenged to work across housing, health, and social care boundaries. Studies have shown that befriending others is a significant role of the neighbourhood volunteer $[4,5]$ although other roles can include those of engaging with professionals in direct care partnerships [6], meeting nonmedical needs [7], manual work [8], and emotional support [9]. Befriending alone can be an effective way of relieving loneliness and isolation for those living in community settings, particularly if living alone, by helping them to communicate and develop social networks. In Australia, those who receive support can be anyone across the age 
span including children, the elderly, and those with a chronic illness.

Volunteering as a productive activity has been associated with social and health benefits for people with better health and greater happiness [10]. Volunteering can provide a meaningful use of time if unable to work or one's family has grown up, release from loneliness following the loss of loved ones, contribution to neighbourhood life [11], the facilitation of personal and others' empowerment [11], and promoting and gaining social connectedness. Consequently, volunteering has additional benefits that emerge for the individual volunteer, such as increased self-esteem, self-efficacy, and satisfaction. The need for volunteers to both give and receive is a fundamental human need in relationships, and the challenge for organisations is therefore to ensure they feel valued, view their volunteering positively, and sustain their interest in continuing to volunteer [11]. Hence, measuring the overall outcomes that result from volunteer programmes remains a major challenge.

Important to the volunteer is the perceived importance of volunteer work and its relationship to pride, and respect [10, 12]. Organizational support and commitment are related to the experience of respect, pride and perceived importance. Overall, studies suggest that volunteer organizations may do well to implement pride and respect in their volunteer policy, for instance, to address the reliability or retention problem [12].

A systematic review of literature reporting on the use of volunteers in support programmes for people with cancer found that few papers described the programmes sufficiently to enable a good understanding of support recipients, volunteers, and what transpired between them [13]. Due to such a lack of information about programmes, or a co-ordinated strategy to develop an understanding of volunteers' needs, and therefore develop a successful recruitment and retention campaign, the current study was designed to assist a community service gain a better understanding of their volunteer service and volunteers' needs from their own perspectives.

The present study was designed to determine how the retention and recruitment of volunteers could be improved by better understanding their motivations for volunteering, satisfaction received, and needs for support.

\section{Methods}

Seeking to enhance the quality of life of eligible people and to prevent their inappropriate admission to long-term residential care, the Community Care Program was established by St John Ambulance, a self-funded charitable organisation in South Australia in 1992. During October-December 2007, at the time of the study, the Program had approximately 330 clients and 320 volunteers in the metropoli$\tan$ area. Volunteers are screened, trained, interviewed, and matched to clients for general interest, visit expectations, and personality. Ethics approval was obtained from the institutional Research Committee.

A mixed methods approach employed a focus group and semistructured questionnaires to collect data from volunteers.
2.1. Focus Group. The focus group discussion with volunteers gathered information to inform the development of a semistructured questionnaire. Five Community Care volunteers were selected from a database of volunteers, with consideration given to selecting a mix of male and female volunteers from different residential areas. The focus group was held at the institution's premises and ran for 1.5 hours. Travel costs were reimbursed and lunch provided. Responses were recorded with consent and later transcribed and analysed for common themes and meanings.

2.2. Participants. All but one volunteer were female $(n=4)$. The volunteers had been part of the Community Care Program for between six months and four years, and each week supported between $1(n=4)$ and $3(n=1)$ clients, providing $1(n=4)$ to $2(n=1)$ outings. None of the volunteers were employed, although one reported currently looking for work.

2.3. Materials. Eight open-ended questions, each of which had several follow-up prompts, were asked of focus group participants. The main questions were as follows.

(1) Would you share with us your reasons for becoming volunteers with the St John Community Care Program?

(2) What is your understanding of the role of the St John volunteer?

(3) How do you work with the Program coordinator and therefore assist the whole team?

(4) In your opinion, how does your role impact on other health services the client may be receiving?

(5) In your opinion, are there any difficulties to the partnerships between yourself and St John that make it hard for you to stay a volunteer? If so, what are they?

(6) Do you have any suggestions for ways the Community Care Program could improve for volunteers?

(7) Do you receive any support from St John for your role?

(8) What is about the Program that keeps you active?

2.4. Questionnaire. A semistructured questionnaire eliciting structured and unstructured responses was developed from information gathered from the literature and the focus group. Questionnaires sought information relating to the individual's sociodemographic factors, motivation for volunteering, why they remained a volunteer, and the type of support received to do their job.

The first section of the questionnaire (Q1-4) asked volunteers for basic demographic information: gender, postcode, work status (i.e., retired, work part-time, home duties, etc.), and how long they had been a volunteer for Community Care.

The following questions asked about volunteers' motivations for becoming a Community Care volunteer (tick box choices included I had spare time and wanted to use it in a positive way, and I had been asked to volunteer by other people who volunteer) and what retained the volunteers in the Community Care Program (i.e., adds another dimension to 
my life). The final question in this section asked whether the participant's expectations of the volunteering experience had been met.

The third part of the survey asked for volunteers' levels of agreement regarding a number of statements relating to their Community Care volunteer orientation. Volunteers were asked to respond to eight statements, including The orientation provided me with the necessary confidence to conduct the volunteer role; role play (or further role play) at orientation would be helpful; the amount of time spent in orientation is too long, on a 4-point Likert scale ranging from strongly agree to strongly disagree.

The next section of the questionnaire (Q12) asked volunteers to answer on the same 4-point Likert scale ranging from strongly agree to strongly disagree whether they would recommend volunteering to others, and whether they planned to continue volunteering (a) for another year, and (b) all being well, for another $2-5$ years.

2.5. Procedure. Questionnaires were posted to 320 Community Care volunteers with a letter of invitation stating the purpose of the survey. A reminder was sent to nonresponders after three weeks. A reply-paid envelope was enclosed with the questionnaire. Completed questionnaires were returned to a designated institutional employee who entered the (deidentified) data into statistical software and stored the papers securely.

All quantitative data from the questionnaire were managed and analysed using SPSS. Descriptive analyses were performed and data are presented by frequency and percentage. The questionnaire allowed respondents to make additional text comments. Content analysis was applied to the narrative data provided for the final question of the survey.

\section{Results}

A response rate of $66.9 \%$ (214) questionnaires was completed and returned although not every question was completed by all. Of the responding volunteers, $81.7 \%$ (174) were female. All were aged over 60 years (range: 63-76 years; mean: 68 years). As shown in Table 1, volunteers were mostly either retired or pensioners $(48.9 \%)$ and women dominated each work category.

Asked how long they had been a volunteer, 47.2\% (100) reported that they had been with the program for less than two years, while fewer had been volunteers for 2-5 years $(31.6 \%, 66)$ or more than 5 years $(21.7 \%, 46)$. Table 2 shows that across all work categories, more volunteers had been in service less than 2 years and the least for five or more years.

3.1. Motivations for Volunteering. Volunteers' most common reasons for being a Community Care volunteer (see Table 3) were to contribute to the community and to those who needed help (81.3\%), to use their own spare time in a positive way $(61.7 \%)$, and to help others in a way that they themselves might need in the future (57.0\%). Females more than males wanted to find companionship after finding a gap in their life.
TABle 1: Characteristics of Neighbourhood Care volunteers $(n=$ 213).

\begin{tabular}{lcccc}
\hline Gender & $n$ & $\%$ & & \\
\hline Female & 174 & $81.7 \%$ & & \\
Male & 39 & $18.3 \%$ & & \\
\hline Work status & $n$ & $\%$ & Female & Male \\
\hline Retired ${ }^{*}$ Pensioner* & 104 & $48.9 \%$ & $75 \%$ & $25 \%$ \\
Work full-time & 34 & $16.0 \%$ & $85.3 \%$ & $14.7 \%$ \\
Work part-time & 41 & $19.2 \%$ & $85.4 \%$ & $14.4 \%$ \\
Home duties* & 20 & $9.4 \%$ & $100 \%$ & \\
Other & 10 & $4.7 \%$ & $80 \%$ & $20 \%$ \\
Unemployed & 4 & $1.9 \%$ & $75 \%$ & $25 \%$ \\
\hline
\end{tabular}

* Pensioner refers to anyone receiving a pension for example, aged, disability.

\# Retired refers to anyone retired from paid work but may not be in receipt of a pension.

*Home duties refers to anyone whose main work role is looking after the family home.

Other reasons for volunteering (15.4\%) included.

Returning the help the Program had given the volunteer's own family: that is, my daughter when young was a Cadet... I wanted to volunteer in respect for what the organisation did for her; the Program assisted me when I was looking after my mother, so I am returning the favour.

Gaining or using experience and/or skills: that is, gain community service experience; provides practical skills I can use in a professional environment; work experience as a carer; I wanted to put into use my recent training in counselling.

Adding to the volunteer's and/or their children's lives: that is, improved self-esteem and confidence; new friendship; to encourage my children and for them to see who and how people need help; it would be good for my young daughter to see and experience caring for older people.

3.2. Supportive Structures. Support for volunteers included programme coordinators and an orientation programme. Volunteers found that the programme coordinator helped them most frequently by setting safe boundaries for clients and families $(70.6 \% ; 151)$, followed by regular phone calls with the volunteer to discuss client wellbeing and other issues $(62.1 \% ; 133)$, and resolving disputes $(53.7 \% ; 115)$.

Volunteers were appreciative that they were offered a range of choices of whom to care for and that coordinators tried to make sure that client and volunteer were compatible in need and in age:

And they ask you if you would like a male or female, or if you'd like someone in a wheel chair. What age? They give you some choice.

"Other" ways programme coordinators helped (15.0\%; 32) included the following:

(i) support for difficult situations: that is, when client becomes difficult; it is my wellbeing discussed with coordinator; if I have problems, my coordinator is always available to me and is very helpful and always available to discuss confidential aspects of clients' situations and to clarify concerns; 
TABLE 2: Time in service as a volunteer compared with work status for both males $(M)$ and Females $(F)(N=179)$.

\begin{tabular}{|c|c|c|c|c|c|c|}
\hline Work status & & Full time & Part time & Retired & Unemployed & Home duties \\
\hline & & $34(16 \%)$ & $13(6 \%)$ & $28(13 \%)$ & $2(1 \%)$ & $18(5 \%)$ \\
\hline \multirow[t]{8}{*}{ Time in service } & Less than 2 years & $F=29(88 \%)$ & $F=11(85 \%)$ & $F=19(68 \%)$ & $F=2(100 \%)$ & $F=16(89 \%)$ \\
\hline & & $M=5(12 \%)$ & $M=2(15 \%)$ & $M=9(32 \%)$ & & $M=2(11 \%)$ \\
\hline & & $9(4 \%)$ & $10(5 \%)$ & $29(14 \%)$ & $2(1 \%)$ & $10(3 \%)$ \\
\hline & $2-5$ years & $F=7(78 \%)$ & $F=7(70 \%)$ & $F=18(62 \%)$ & $F=1(50 \%)$ & $F=10(100 \%)$ \\
\hline & & $M=2(22 \%)$ & $M=3(30 \%)$ & $M=11(38 \%)$ & $M=1(50 \%)$ & \\
\hline & & $1(0.5 \%)$ & $3(1 \%)$ & $18(6 \%)$ & & $2(1 \%)$ \\
\hline & $5+$ years & $F=1(100 \%)$ & $F=2(67 \%)$ & $F=13(72 \%)$ & & $F=2(100 \%)$ \\
\hline & & & $M=1(33 \%)$ & $M=5(28 \%)$ & & \\
\hline
\end{tabular}

TABle 3: Neighbourhood Care volunteers' motivations for volunteering $(n=214)$.

\begin{tabular}{lcccc}
\hline Motivations & $n$ & $\% *$ & Female & Male \\
\hline $\begin{array}{l}\text { To contribute to the } \\
\text { community and those } \\
\text { who need help }\end{array}$ & 173 & $81.0 \%$ & $81.5 \%$ & $18.5 \%$ \\
$\begin{array}{l}\text { To use spare time in a } \\
\text { positive way }\end{array}$ & 132 & $61.7 \%$ & $81.8 \%$ & $18.2 \%$ \\
$\begin{array}{l}\text { To help others in a way } \\
\text { that I might need help } \\
\text { one day }\end{array}$ & 121 & $57.0 \%$ & $83.5 \%$ & $16.5 \%$ \\
$\begin{array}{l}\text { To share companionship } \\
\text { after finding a gap in my } \\
\text { own life }\end{array}$ & 44 & $20.6 \%$ & $91 \%$ & $9 \%$ \\
$\begin{array}{l}\text { Was asked to volunteer } \\
\text { through my church }\end{array}$ & 4 & $1.9 \%$ & $75 \%$ & $25 \%$ \\
$\begin{array}{l}\text { Was asked to volunteer } \\
\text { by others who were } \\
\text { already volunteering }\end{array}$ & 15 & $7.0 \%$ & $80 \%$ & $20 \%$ \\
\begin{tabular}{l} 
Other \\
\hline
\end{tabular} & 33 & $15.4 \%$ & $78.8 \%$ & $21.2 \%$ \\
\hline
\end{tabular}

*NB: multiple responses allowed.

(ii) meetings and training: that is, regular volunteer meetings with the chance to meet other volunteers... meetings alone if desired, personal development at meetings with other related agencies, and provide information sessions with service providers;

(iii) liaison with the client and their family: that is, pass on concerns to family who may be unaware of some circumstances; discuss care issues with family and volunteer; and contact family and liaise with them regularly.

From the types of comments made it is evident that programme coordinators are central to the volunteers' successful experience of volunteering.

Volunteers' views on the orientation programmes provided were almost entirely positive, with the majority agreeing that the orientation was helpful $(98.6 \% ; 211)$. Only $8.4 \%$ ( $n=18$ ) said that the orientation was too long, although $13.1 \%(n=28)$ thought it was too short, and $28.5 \%(n=61)$ thought it would be useful to include role play (or more role play) in the orientation.
TABle 4: Volunteers' reasons for remaining an active part of the Community Care program.

\begin{tabular}{lcccc}
\hline Reasons & $n$ & $\%$ & Female & Male \\
\hline $\begin{array}{l}\text { Get satisfaction from } \\
\text { helping someone else }\end{array}$ & 191 & $90.1 \%$ & $80.6 \%$ & $19.4 \%$ \\
$\begin{array}{l}\text { Like to see the client's } \\
\text { enjoyment }\end{array}$ & 169 & $79.7 \%$ & $82.8 \%$ & $17.2 \%$ \\
$\begin{array}{l}\text { Get friendship and } \\
\text { companionship from } \\
\text { clients }\end{array}$ & 134 & $63.2 \%$ & $84.8 \%$ & $19.6 \%$ \\
$\begin{array}{l}\text { Adds another dimension } \\
\text { to my life }\end{array}$ & 133 & $62.7 \%$ & $80.5 \%$ & $19.5 \%$ \\
\begin{tabular}{l} 
Other \\
\hline
\end{tabular} & 25 & $15.4 \%$ & $76 \%$ & $24 \%$ \\
\hline
\end{tabular}

3.3. Remaining a Volunteer. Table 4 displays volunteers' responses on why they remained an active Community Care volunteer. The most commonly chosen reason was the satisfaction they gained from helping others $(89.7 \%$; 192).

Volunteers' "other" reasons for staying active (15.4\%) included enjoyment of various aspects of volunteering: for example, some challenging intellectual discussion; it is great putting something back into the community; I feel I am needed and I need to be needed; it keeps me active and out of depression; I like to believe in some small way that I'm a help and give some extra enjoyment to my client; and personal benefit and knowledge: for example, I have a better understanding of what life is like for our elderly people in the neighbourhood; I learn and grow from knowing others and spending time with them; working with clients with a range of issues broadens my counselling experience.

3.4. Satisfaction with Volunteering. All two hundred and fourteen volunteers indicated that they would recommend volunteering in the Community Care Program to other people. The majority $(96.2 \%, 206)$ thought that they would continue to volunteer with the Program for another year, and 92.5\% $(n=198)$ indicated that all being well, they planned to volunteer for another 2-5 years.

The majority $(91.1 \% ; 195)$ agreed that their expectations had been met, while 2.3\% $(n=5)$ disagreed, and $6.5 \%(n=$ 13) were unsure. 


\section{Discussion}

By exploring volunteers' perspectives, this project identified potential recruitment and retention issues for a self-funded charitable organisation. Volunteers expressed pride and enjoyment in the services they provided, appreciation for those who assisted them, and described the positive aspects of volunteering. Motivations for volunteering included deep, personal reasons such as coping after the loss of a partner but also because they wanted to give back what they themselves had received when in need. Barriers to providing services included accessing adequate training and development and the financial costs to themselves. Volunteers were matched to clients for general interest, visit expectations, and personality and spent three to four hours on average per week socializing with and supporting clients. Similarly, a Canadian study found that (1) engaging with others in a care partnership, (2) responding to residents' preferences and care needs with limited resources, and (3) maintaining residents' connections with the community were important roles performed by volunteers [6].

Of particular interest in this Australian study is that the volunteers are of a similar age or older than those they care for. Volunteering as a productive activity in life has been associated with social and health benefits for older people [14]. Volunteers in the reported study were aged between 63 and 76 years with a mean of 68 years and their reasons for volunteering included wanting to help others, fill a gap in their lives after losing a partner but also because volunteering kept them active, and alert and connect with people. Of significance is that nearly half were retired or pensioners, indicating that having time to volunteer is instrumental to being able to do so. The fact that, across all work categories, more volunteers were active for less than two years could indicate early burnout, inadequate support or, due to the age of the volunteers, their own declining health. Interestingly, this does not support the $92.5 \%$ who indicated that all being well, they planned to volunteer for another $2-5$ years.

The fact that some participants reported that they would like more opportunity to mix with fellow volunteers indicated a need for peer support structures which could be provided through the Community Care Program or an external body. This has ramifications for the volunteer "army" of the future which is needed to support an increasing elderly population wishing to remain living in the community and raises the question "who will care for the carers"? To promote volunteer recruitment and hopefully younger persons, flexible options with regard to differences in time availability and lifestyle should be considered [15].

Confirming beliefs [16], that volunteering positively affects health and psychological well-being, volunteers found that they were helped by the very people they themselves were helping. Befriending in the form of providing companionship, social activities, and human contact was a primary role as well as promoting positive emotional well-being. The values of befriending schemes such as the reported Community Care Program are well recognised and potentially an effective way of combating loneliness and isolation and helping individuals to develop social networks [5].
Volunteers reported personal rewards from the work itself and the relationships developed with clients who showed them significant levels of trust and confidence.

With an increasing number of elderly, frail, or disabled people living in the community, the need for supportive services that assist them to retain their independence safely rises. With this increase comes a need for unpaid volunteers who are able to provide competent, personalised care. Retaining and recruiting this "army" of volunteers is a challenge for the future, and an understanding of their motivations to volunteer and needs for a satisfactory experience is paramount to a successful volunteer programme.

Volunteers also encountered challenges that included role demands, role-ability fit, emotional concerns, and limited organizational resources and structural obstacles. This finding suggests that care must be taken to ensure that the volunteer role meets the needs, skills, and abilities of the individual volunteering to ensure the best outcome for both parties [17]. Although supportive structures such as training and development activities and programme coordinators were in place, there is a need for counselling to support volunteers grieving for a client. Resources such as practice guidelines and more rigorous training and development focusing on reality situations were also suggested. Adequate reimbursement for expenses was an issue required to be addressed. In order for volunteers to view their volunteering positively and to sustain their interest there needs to be a balance between giving and taking [18]. Thus the volunteering experience can be empowering and make a difference for the elderly and others in the community.

4.1. Limitations. A limitation of this study is that it investigated one group of volunteers working for one institution's community care programme and may not be representative of other types of community care programmes and volunteers. Not uncommonly in survey research, a third of the sample population did not respond, possibly creating a response bias in that this group may have had significantly different views. Although the vast majority of volunteers agreed that their expectations had been met, volunteers were not asked what their expectations had been, and whether those expectations had been positive or negative. There is also a possibility of investigator bias in that the researcher interpreted narrative responses in a way that matched her preconceived notions. Finally, although there is congruence with studies from other countries, the results may mainly be applicable to the Australian system, as there is probability of differences between this volunteer programme and others.

\section{Conclusion}

Despite the limitation, the majority of volunteers agreed that their expectations of the volunteering experience had been met. Their suggestions for programme improvement related to the orientation, training, communications, and provision of guidelines. In addition they wanted more opportunities to get to know other volunteers and increased fuel allowances. Ideas for promoting the Program to the community were 
also made. Appropriate support structures such as approachable, communicative, responsive coordinators, meetings and training and development are important for a positive experience.

The inherent nature of the work of the Community Care Program provides volunteers with satisfaction, enabling them to be able to continue with their roles. Incentives are required as a way to attract or retain volunteers and to show appreciation for their services. The project has highlighted that the values of volunteering include contributing to the community, using spare time positively, and helping others. These are the aspects that need to be promoted to attract more volunteers.

Further investigation and appraisal as to the viability of some of the incentives suggested, such as increasing the fuel subsidy, increasing training opportunities, and improving some aspects of communication and follow-up, to make programs as volunteer-friendly as possible is recommended. Further investigation as to why volunteers may not pursue volunteering and a comparison between younger and older person's reasons for volunteering would contribute to the field's body of knowledge.

Community Care Program volunteers are an important link to enabling the frail, elderly, or disabled to continue to live independently at home. Meeting their needs assists them to continue volunteering and organisations in the recruitment and retention of volunteers.

\section{References}

[1] R. A. Harootyan and E. B. James, "Volunteer Activity by Older Adults," in Encyclopedia of Gerontology, pp. 660-667, Elsevier, New York, NY, USA, 2007.

[2] D. Field, C. Ingleton, and D. Clark, "The costs of unpaid labour: the use of voluntary staff in the King's Mill Hospice," Health and Social Care in the Community, vol. 5, no. 3, pp. 198-208, 1997.

[3] S. A. Tomas, L. Kennedy, and C. Colomer Revuelta, "Volunteerism and the reorientation of health services," Aten Primaria, vol. 22, no. 7, pp. 450-456, 1998.

[4] A. V. Taggart, S. D. Short, and L. Barclay, "“She has made me feel human again": an evaluation of a volunteer home-based visiting project for mothers," Health and Social Care in the Community, vol. 8, no. 1, pp. 1-8, 2000.

[5] T. Bradshaw and G. Haddock, "Is befriending by trained volunteers of value to people suffering from long-term mental illness?" Journal of Advanced Nursing, vol. 27, no. 4, pp. 713-720, 1998.

[6] S. A. Chapman, N. Keating, and J. Eales, "Client-centred, community-based care for frail seniors," Health and Social Care in the Community, vol. 11, no. 3, pp. 253-261, 2003.

[7] R. Wexberg, "Bridging the gaps in geriatric care. Volunteers help meet the elderly's nonmedical needs," Health Progress, vol. 77, no. 6, pp. 38-41, 1996.

[8] P. Hoad, "Drawing the line: the boundaries of volunteering in the community care of older people," Health and Social Care in the Community, vol. 10, no. 4, pp. 239-246, 2002.

[9] M. Faulkner and S. Davies, "Social support in the healthcare setting: the role of volunteers," Health and Social Care in the Community, vol. 13, no. 1, pp. 38-45, 2005.
[10] F. Borgonovi, "Doing well by doing good. The relationship between formal volunteering and self-reported health and happiness," Social Science and Medicine, vol. 66, no. 11, pp. 2321-2334, 2008.

[11] J. Downie, K. Clark, and K. Clemenston, "Volunteerism: "community mothers" in action," Contemporary Nurse, vol. 18, no. 1-2, pp. 188-198, 2004.

[12] E. J. Boezeman and N. Ellemers, "Volunteering for charity: pride, respect, and the commitment of volunteers," Journal of Applied Psychology, vol. 92, no. 3, pp. 771-785, 2007.

[13] M. L. Macvean, V. M. White, and R. Sanson-Fisher, "Oneto-one volunteer support programs for people with cancer: a review of the literature," Patient Education and Counseling, vol. 70, no. 1, pp. 10-24, 2008.

[14] J. Warburton and N. M. Peel, "Volunteering as a productive ageing activity: the association with fall-related hip fracture in later life," European Journal of Ageing, vol. 5, no. 2, pp. 129136, 2008.

[15] S. Lee, T. Saito, M. Takahashi, and I. Kai, "Volunteer participation among older adults in Japan: an analysis of the determinants of participation and reasons for non-participation," Archives of Gerontology and Geriatrics, vol. 47, no. 2, pp. 173187, 2008.

[16] J. A. Piliavin and E. Siegl, "Health benefits of volunteering in the Wisconsin longitudinal study," Journal of Health and Social Behavior, vol. 48, no. 4, pp. 450-464, 2007.

[17] J. Crook, R. Weir, D. Willms, and T. Egdorf, "Experiences and benefits of volunteering in a community AIDS organization," Journal of the Association of Nurses in AIDS Care, vol. 17, no. 4, pp. 39-45, 2006.

[18] J. Merrell, "“You don't do it for nothing”: women's experiences of volunteering in two community well woman clinics," Health and Social Care in the Community, vol. 8, no. 1, pp. 31-39, 2000. 


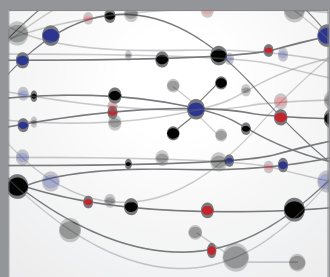

The Scientific World Journal
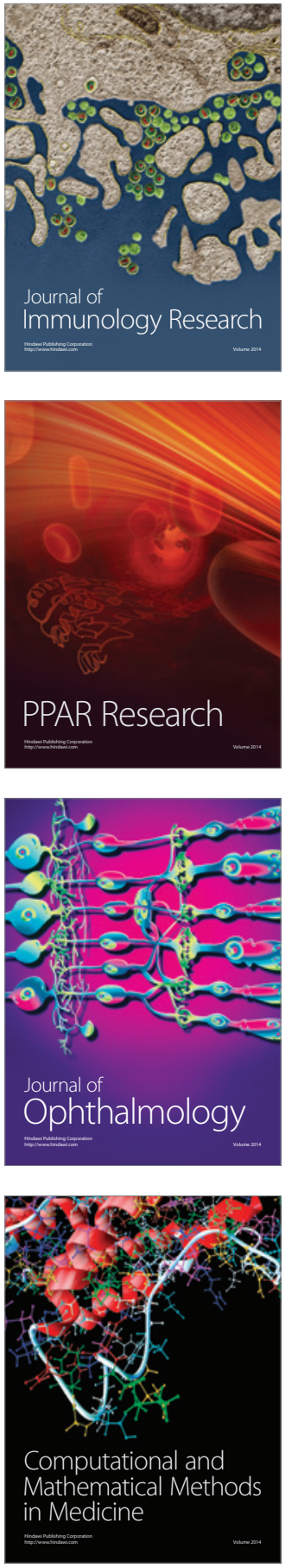

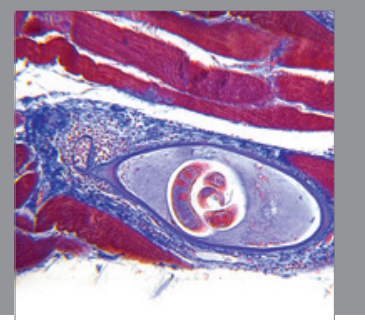

Gastroenterology

Research and Practice
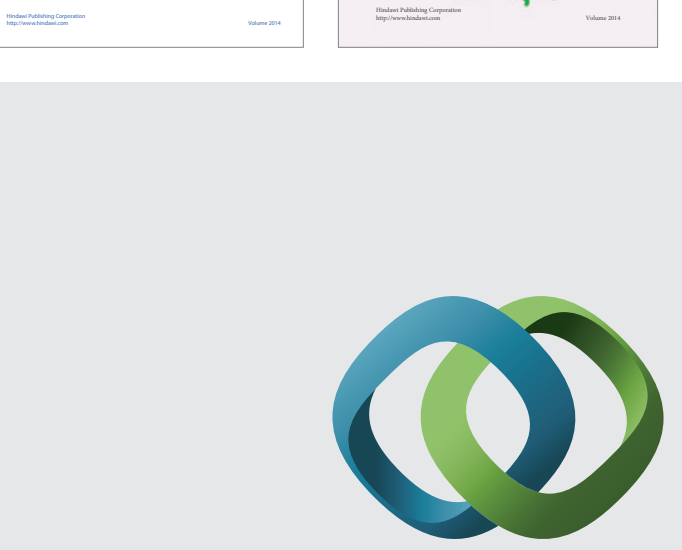

\section{Hindawi}

Submit your manuscripts at

http://www.hindawi.com
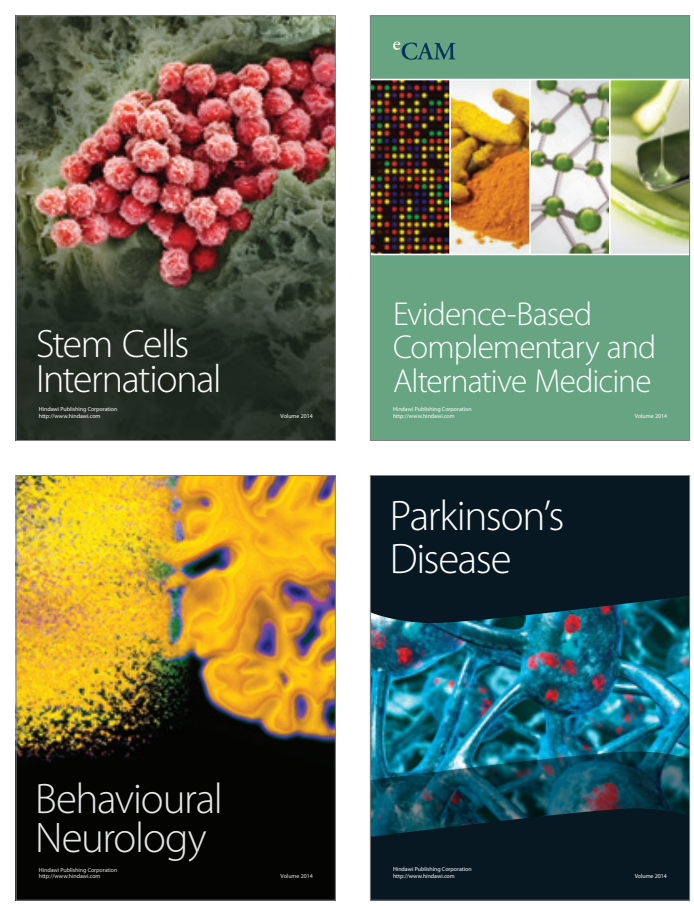

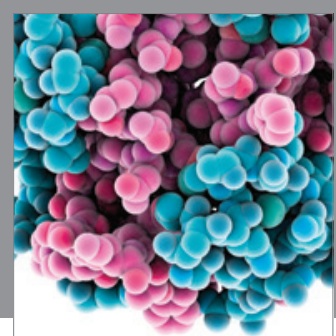

Journal of
Diabetes Research

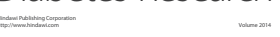

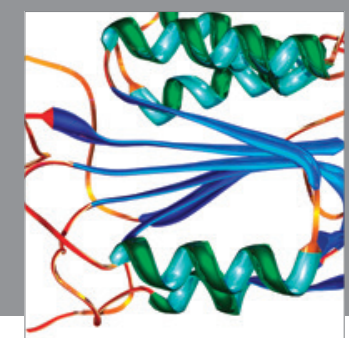

Disease Markers
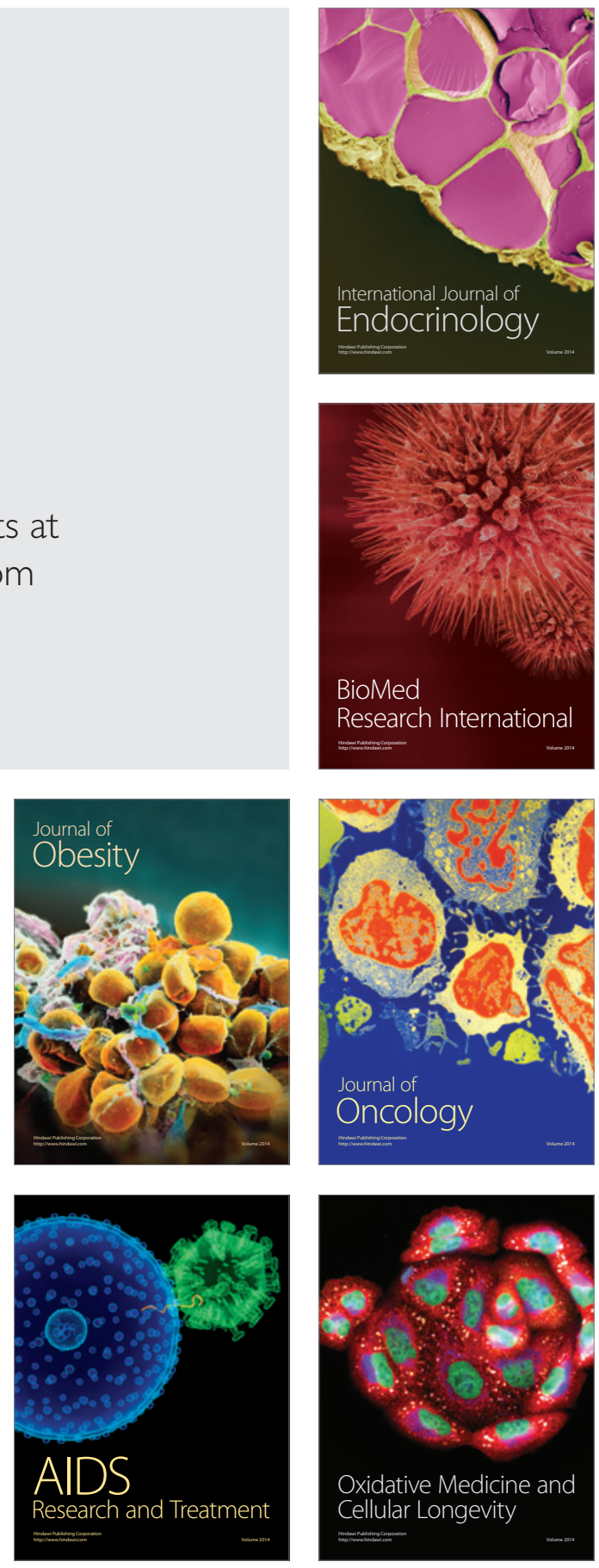